\title{
Perforation of the Gallbladder Due to a Swallowed Sewing Needle: Case Report
}

\author{
Halil Doğan', Kasım Çağlayan², Banu Fatma Işsler³, Hasan Arslan², Doğaç Niyazi Özüçelik \\ 'Department of Emergency Medicine, Bakırköy Dr. Sadi KonukTraining and Research Hospital, İstanbul, Turkey \\ 2Department of General Surgery, Kars State Hospital, Kars, Turkey \\ 3Department of Anesthesia and Reanimation, Kars State Hospital, Kars, Turkey
}

\begin{abstract}
Introduction: Ingestion of foreign bodies is a common problem, particularly among the elderly, pediatric, and psychiatric populations. Most of the foreign bodies pass spontaneously and uneventfully within a week. Perforation of the gallbladder by an ingested sewing needle is extremely rare, and a single case has been reported in the literature.

Case Report: We report a rare case of 30-year-old woman who accidentally ingested a sewing needle, which silently perforated the stomach and migrated to the gallbladder.

Conclusion: For foreign bodies in the stomach and duodenum, the general management is usually conservative. In situations such as those in our presented case, if there is a history of foreign body ingestion and failure of its progress as well as the presence of acute abdomen, there may be an indication for surgery.
\end{abstract}

Keywords: Foreign bodies, gallbladder, perforation, sewing needle

Received: 22.02.2016 Accepted: 01.04.2016 Available Online Date: 15.07.2016

\section{Introduction}

Swallowing a foreign body, particularly in among the elderly and children and people under psychiatric treatment, is a frequently encountered problem. The ingested foreign body is usually discarded from the gastrointestinal system within a week (1). Organ perforations should be kept in mind in cases with abdominal pain when the progress of the foreign body cannot be visualized by radiography (2). In very few of these patients, foreign bodies fail to progress; therefore, there is an indication of surgical intervention only in $1 \%-14 \%$ of cases $(2,3)$. Fortunately, swallowed foreign bodies rarely perforate the organs and migrate into the abdominal cavity; however, if it happens, laparotomy is indicated $(1,4)$. Although isolated perforations of hollow organs such as the stomach have been reported due to swallowed sewing needles, it is very uncommon for co-existent perforations of the stomach and gallbladder to occur $(5,6)$. We attempted to present the case of a patient coming to the emergency room with abdominal pain and a one-month history of a swallowed sewing needle, leading to the perforation of both the stomach and the gallbladder that required cholecystectomy and gastrorrhaphy. We also discussed a case with a rare complication of a digested and migrated sewing needle.

\section{Case Report}

A 30-year-old woman was admitted to the emergency department because of abdominal pain and a history of an accidentally swallowed sewing needle one month ago. She was followed up at her local hospital and was referred to our hospital because of the failure of the progress of the foreign body. A physical examination showed slight right upper quadrant tenderness, and a positive Murphy's sign. Blood analysis showed increased white blood count: 12000 (4000-11000) K/ LL]. Other biochemical and hematological parameters were within the normal ranges. She underwent abdominal plain X-ray scan, which revealed radioopaque objects in the liver area in the form of the sewing needle (Figure 1). We learned that the patient accidentally swallowed a sewing needle one month ago. The patient was clinically stable, and semi-urgent laparotomy was planned on the same day. 


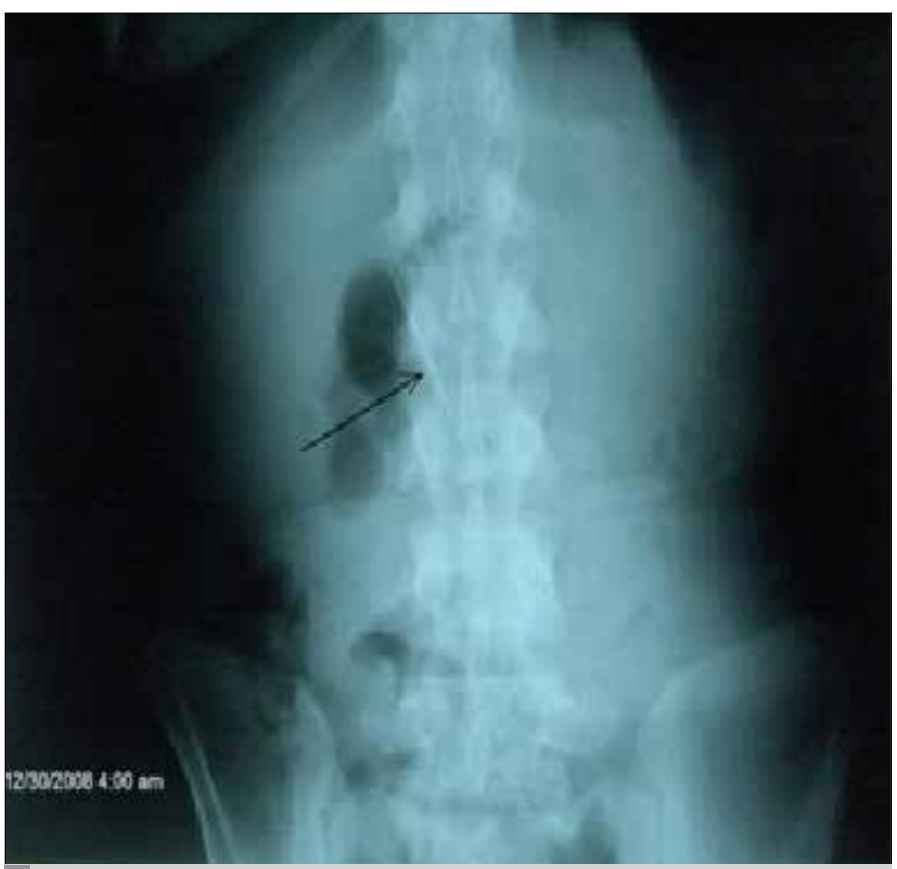

FIGURE 1. Plain abdominal radiograph showing the needle in the liver area (arrow)

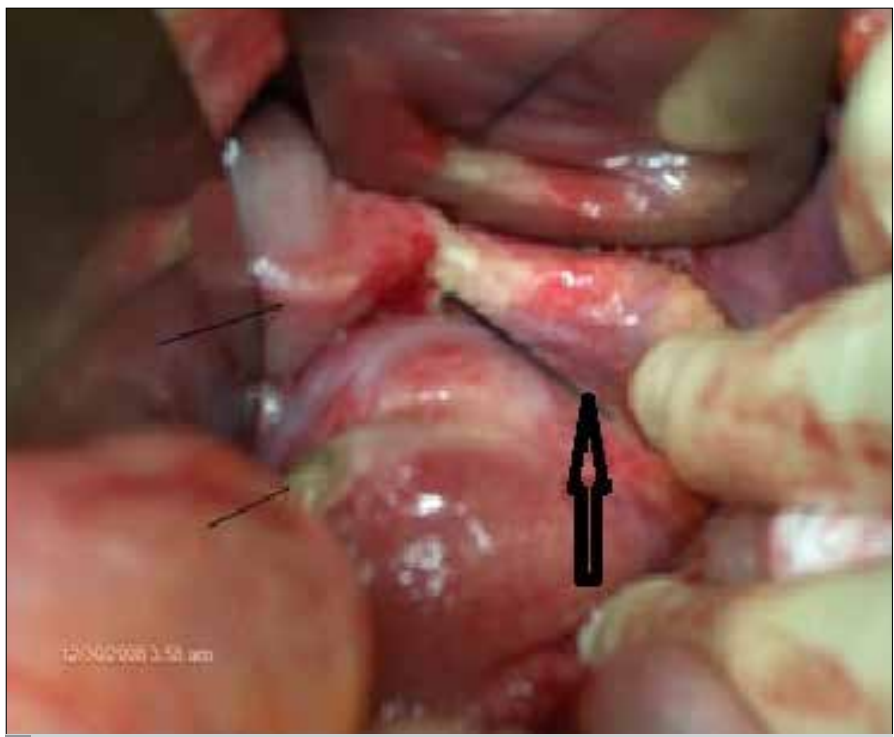

FIGURE 2. The sewing needle seen in the gallbladder (big arrow) and the side of the gastric perforation (small arrows)

On laparotomy, the needle was found in the gallbladder, and the end of the needle could be palpated, and the site of gastric perforation could be seen (Figure 2). We performed cholecystectomy and primary gastrorrhaphy. Antibiotics and anti-inflammatory medications were given from the first day. Oral feeding was started on the third postoperative day. The postoperative period was uneventful, and the patient was discharged on the seventh day after the operation.

\section{Discussion}

The perforation of the gallbladder by an ingested sewing needle is an extremely rare complication (7). Some etiological and predispos- ing factors causing gallbladder perforation include calculous and acalculous cholecystitis, blunt and sharp abdominal trauma, collagen tissue disorders, malignancy, corticosteroid therapy, impaired vascular supply to the gallbladder, diabetes mellitus, old age, and male gender $(5,7,8)$. The mortality rate of gallbladder perforation is between $15 \%$ and $20 \%(6-8)$. There are no classical symptoms and signs associated with gallbladder perforation. Patients may be acutely ill, or they may have an insidious onset. An acute onset may be diagnosed by right upper quadrant pain, fever, a palpable right upper quadrant mass, and tenderness, similar to our case $(7,8)$.

Complications of gastrointestinal foreign bodies are still unclear. A detailed history and wise planned serial imaging are crucial steps after foreign body ingestion. Ultrasonography methods may help diagnose the presence of a gallbladder perforation by displaying distention and fluid collection around the gallbladder as well as free fluid in the peritoneal cavity (5-8). In our case, due to the lack of serial imaging, it resulted in a delayed diagnosis.

Most ingested foreign bodies (toys, dentures, and cutlery items) pass through the gut without causing any complications (9). Approximately $1 \%-3 \%$ of these either obstructs or causes a perforation in certain anatomical locations such as the duodenum, ileocecal junction, and appendix. In a literature search, two perforation cases, owing to the ingestion of a fish bone and a sewing needle were found. Only one case of a swallowed sewing pin by a 13 year-old girl was observed in the gallbladder without any fistula through the stomach. This case was managed by laparoscopy and cholecystectomy. We present the second case of a gallbladder perforation taking place by the trans-gastric migration of an ingested sewing needle. For foreign bodies that have been ingested and are in the stomach and duodenum, general management is usually the conservative approach. There may be an indication for surgery in situations, as in our present case, if there is a history of foreign body ingestion and failure of its progression as well as the presence of acute abdomen $(1,5)$. Traditional surgical treatment requires laparotomy for foreign body removal, but the laparoscopic approach for intestinal foreign bodies has also been reported $(1,10)$. In our case, we performed open cholecystectomy and primary gastrorrhaphy. The postoperative period was uneventful, and the patient was discharged on the seventh day after the operation.

\section{Conclusions}

The transition of ingested foreign objects into the abdominal cavity resulting in the perforation of an intra-abdominal organ is rare and frequently necessitates laparotomy. If there is a history of sewing needle ingestion and failure of its progress and the presence of an acute abdomen, surgeons must carefully evaluate the possibility of a gallbladder perforation.

Informed Consent: Written informed consent was obtained from patient who participated in this case.

Peer-review: Externally peer-reviewed.

Author contributions: Concept - H.D., K.Ç., F.B.I., H.A.; Design - H.D., K.Ç., F.B.I.; Supervision - H.D., K.Ç., F.B.I.; Resource - H.D., K.Ç., F.B.I., D.N.O.; Materials - H.D., 
K.Ç., F.B.I., H.A.; Data Collection\&/or Processing - H.D., K.Ç.F., B.I., H.A.; Analysis\&/or Interpretation - H.D., K.Ç., F.B.I., H.A.; Literature Search - H.D., K.Ç., F.B.I., D.N.O.; Writing - H.D., D.N.O.; Critical Reviews - H.D., D.N.O.

Conflict of Interest: The authors declared no conflict of interest.

Financial Disclosure: The authors declared that this study has received no financial support.

\section{References}

1. Chintamani, Singhal V, Lubhana P, Durkhere R, Bhandari S. Liver abscess secondary to a broken needle migration a case report. BMC Surg 2003; 3: 8. [CrossRef]

2. Furihata M, Tagaya N, Furihata T, Kubota K. Laparoscopic removal of an intragastric foreign body with endoscopic assistance. Surg Laparosc Endosc Percutan Tech 2004; 14: 234-7. [CrossRef]

3. Vizcarrondo FJ, Brady PG, Nord HJ. Foreign bodies of the upper gastrointestinal tract. Gastrointest Endosc 1983; 29: 208-10. [CrossRef]
4. Iafrati MD, Fabry SC, Lee YM, Obrien JW, Schwaitzberg SD. A novel approach to the removal of sharp foreign bodies from the stomach using a combined endoscopic and laparoscopic technique. Gastrointest Endosc 1996; 43: 67-70. [CrossRef]

5. Karacay S, Topçu K, Sözübir S. A rare complication of an ingested foreign body: gallbladder perforation. Case Rep Gastrointest Med 2013; 672572. [CrossRef]

6. Kunizaki M, Kusano H, Azuma K, Fukuoka H, Araki M, Hidaka S, et al. Cholecystitis caused by a fish bone. Am J Surg 2009; 198: e20-e22. [CrossRef]

7. Roslyn J, Busuttil RW. Perforation of the gallbladder: a frequently mismanaged condition. Am J Surg 1979; 137: 307-12. [CrossRef]

8. Kochar K, Vallance K, Mathew G, Jadhav V. Intrahepatic perforation of the gall bladder presenting as liver abscess: case report, review of literature and Niemeier's classification. Eur J Gastroenterol Hepatol March 2008; 20: 240-4. [CrossRef]

9. Rahalkar MD, Pai B, Kukade G, Jadhav V. Sewing Needles as Foreign Bodies in the Liver and Pancreas. Clin Radiol 2003; 58: 84-6. [CrossRef]

10. Crankson SJ. Hepatic foreign body in a child. Paed Surg Int 1997; 12: 426-7. [CrossRef] 